\title{
Low bone mineral density is related to male gender and decreased functional capacity in early spondylarthropathies
}

\author{
M. A. C. van der Weijden • J. C. van Denderen • \\ W. F. Lems • M. W. Heymans • B. A. C. Dijkmans • \\ I. E. van der Horst-Bruinsma
}

Received: 26 April 2010 /Revised: 25 June 2010 / Accepted: 7 July 2010 / Published online: 10 August 2010

(C) The Author(s) 2010. This article is published with open access at Springerlink.com

\begin{abstract}
The objective of this study was to determine the prevalence and risk factors of low bone mineral density (BMD) in patients with spondylarthropathies ( $\mathrm{SpA}$ ) at an early stage of disease. In this cross-sectional study, the BMD of lumbar spine and hips was measured in 130 consecutive early $\mathrm{SpA}$ patients. The outcome measure BMD was defined as (1) osteoporosis, (2) osteopenia, and (3) normal bone density. Logistic regression analyses were used to investigate relations between the following variables: age, gender, disease duration, diagnosis, HLA-B27, erythrocyte sedimentation rate (ESR), C-reactive protein (CRP), Bath Ankylosing Spondylitis Disease Activity Index (BASDAI), Bath Ankylosing Spondylitis Functional Index (BASFI), Bath Ankylosing Spondylitis Metrology Index (BASMI), extra-spinal manifestations and medication, with outcome measure low BMD (osteopenia and/or osteoporosis). The $\mathrm{SpA}$ population had a median time since diagnosis of 6.6 months and a disease duration of 6.3 years.
\end{abstract}

M. A. C. van der Weijden - W. F. Lems - B. A. C. Dijkmans •

I. E. van der Horst-Bruinsma $(\square)$

Department of Rheumatology, VU University Medical Center,

Room 3A-64, PO Box 7057, 1007 MB Amsterdam,

The Netherlands

e-mail: ie.vanderhorst@vumc.nl

J. C. van Denderen · W. F. Lems • B. A. C. Dijkmans Department of Rheumatology, Jan van Breemen Institute, Amsterdam, The Netherlands

M. W. Heymans

Department of Epidemiology and Biostatistics,

VU University Medical Center, EMGO Institute,

Amsterdam, The Netherlands
In total, $9 \%$ of the early $\mathrm{SpA}$ patients had osteoporosis, $38 \%$ osteopenia, and 53\% normal BMD. On univariate analyses, male gender, diagnosis of ankylosing spondylitis, increased CRP, high BASFI, and high BASMI were significantly associated with low BMD. Factors showing a relation with low BMD in the multivariate model were male gender (OR 4.18, 95\% confidence interval (CI) 1.73-10.09), high BASMI (OR 1.54, 95\% CI 1.14-2.07), and high BASFI (OR 1.18, 95\% CI 1.00-1.39). In early SpA patients, a high frequency (47\%) of low BMD in femur as well as in lumbar spine was found. Low BMD was associated with male gender and decreased functional capacity. These findings emphasize the need for more alertness for osteoporosis and osteopenia in spondylarthropathy patients at an early stage of the disease.

Keywords Ankylosing spondylitis · Bone mineral density · Osteoporosis $\cdot$ Spondylarthropathies

\section{Introduction}

Spondylarthropathies (SpA) comprise a group of interrelated chronic inflammatory diseases, i.e. ankylosing spondylitis (AS), psoriatic arthritis, SpA associated with inflammatory bowel diseases (IBD), reactive arthritis, juvenile onset SpA, and undifferentiated SpA. These diseases share several clinical features such as inflammation of the axial joints, asymmetric oligoarthritis (especially of the lower extremities), and enthesitis.

Loss of bone mass (osteopenia or osteoporosis) in spine and femur is a well-recognized and important complication of long-standing AS $[1,2]$ because a reduced bone mass 
will increase the risk of vertebral fractures [1, 3-5]. In addition, vertebral deformities will contribute to hyperkyphosis and functional loss [4, 6], which, in rare cases, may even cause neurological deficits due to spinal cord injuries [7-9].

In long-standing AS, reduced bone mass is reflected by low bone mineral density (BMD), particularly in the hips. Lumbar BMD values will often be normal or even high as the presence of bridging syndesmophytes may mask osteoporosis in AS patients at an advanced stage of the disease $[1,2,10,11]$.

Bone loss is a well-known complication of AS with a long disease duration; however, little is known about the degree of osteoporosis in the total group of SpA patients. Until now, no studies are available quantifying the magnitude of osteoporosis in a population of early SpA patients. Therefore, the aim of this study was to investigate the prevalence of osteopenia and osteoporosis and their demographic and disease-related risk factors in SpA patients at an early stage of the disease.

\section{Materials and methods}

\section{Study population}

Patients with a recent diagnosis of $\mathrm{SpA}$ (according to the ESSG criteria) [12] as well as inflammatory back pain [13] were consecutively enrolled in a prospective early spondylarthropathy cohort at the Jan van Breemen Institute, a major outpatient rheumatology clinic in Amsterdam. The diagnosis of spondylarthropathy consisted of AS, undifferentiated SpA, patients with inflammatory back pain, and psoriatic arthritis (axial disease: all psoriatic arthritis patients fulfilled the radiographic modified New York criteria) [14], inflammatory bowel diseases, or reactive arthritis. Patients with mechanical back pain were excluded from the study. For the present study, we used clinical characteristics and bone mineral density measurements made with dual X-ray absorptiometry (DXA) scans from all patients at inclusion.

At inclusion, a verified medical history, physical examination, laboratory assessment, radiographs of the spine, and a DXA scan were obtained from all SpA patients. The following patient characteristics were collected: demographics (i.e., gender and age), disease-related variables, such as time since diagnosis, disease duration (time since first complaints), and presence of peripheral arthritis, inflammatory bowel diseases, psoriasis, and uveitis. In addition, disease activity score Bath Ankylosing Spondylitis Disease Activity Index (BASDAI) [15] and functional capacity scores Bath Ankylosing Spondylitis Functional Index (BASFI) [16] and Bath Ankylosing Spondylitis
Metrology Index (BASMI) [17] were collected. Laboratory assessment included erythrocyte sedimentation rate (ESR), C-reactive protein (CRP), and HLA-B27 antigen. Other possible BMD-related variables were obtained, such as data on previous peripheral or vertebral fractures, menopausal status, drug treatment, i.e., use of anti-osteoporotic, diseasemodifying anti-rheumatic drugs (DMARDs), non-steroidal anti-inflammatory drugs (NSAIDs), corticosteroids, and tumor necrosis factor alpha blocking agents (biologicals).

The study protocol was approved by the local Medical Ethics Committee, and all participants gave their permission by signing a form of informed consent.

\section{Outcome measure}

The outcome measure BMD was obtained from the lumbar spine (L2-L4) and the left proximal femur using DXA equipment (Lunar DPX-IQ, Madison, Wisconsin, USA), which was certified for the study. The results were given as BMD $\left(\mathrm{g} / \mathrm{cm}^{2}\right), T$ scores and $Z$ scores. The $T$ score corresponds to the number of standard deviations (SD) rom any result of the peak bone mass, and the $Z$ score is the $T$ score with a correction for age and weight. $T$ and $Z$ score estimations were computed from a large pooled US/Northern Europe (UK/Scandinavia) reference population and were adjusted for gender (as supplied by the manufacturer). Osteopenia and osteoporosis were defined according to the World Health Organization: (1) osteoporosis ( $T$ score $\leq-2.5$ in the spine and/or hip), (2) osteopenia $(-2.5<T$ score $<-1.0$ in the spine and/or hip, without osteoporosis), and (3) normal bone density ( $T$ score $\geq-1.0$ both in spine and hip) [18].

\section{Statistical analysis}

Data are expressed as mean (standard deviation) or median (interquartile ranges) as appropriate. For logistic regression, the BMD data were dichotomized as normal bone density (indicated by 0 ) and low bone density (osteoporosis and/or osteopenia, indicated by 1). Differences in baseline characteristics between $\mathrm{SpA}$ patients with osteopenia and/or osteoporosis (low BMD) and SpA patients with normal BMD were evaluated using independent $t$ tests for normally distributed variables, Mann-Whitney $U$ tests for skewed variables, and Pearson Chi-square tests for dichotomous variables. Univariate logistic regression analyses were performed to investigate associations between the presence of low BMD and disease-related factors $(p<0.05$ was considered statistically significant). Multivariate logistic regression analyses were done by backward selection, removing variables that showed an association with the outcome measure with a $p$ value above 0.10 . All analyses were done using SPSS 14.0 software. 


\section{Results}

Characteristics of the early SpA cohort

The baseline characteristics of $130 \mathrm{SpA}$ patients included in the study show a mean age of 38.0 (9.1), the majority being male (66\%), having a short time since diagnosis (6.6 months) and a short disease duration (6.3 years) (Table 1). The SpA group consisted of $72 \%$ AS patients, $12 \%$ undifferentiated spondylarthropathies, $8 \%$ (axial) psoriatic arthritis, 4\% spondylarthropathies with inflammatory bowel diseases, and $4 \%$ reactive arthritis.

Table 1 Baseline characteristics of early SpA patients

\begin{tabular}{|c|c|}
\hline & $N=130$ \\
\hline \multicolumn{2}{|l|}{ Demographic variables } \\
\hline $\mathrm{Men}^{\mathrm{a}}$ & $86(66)$ \\
\hline $\mathrm{Age}^{\mathrm{b}}$ (years) & $38.0(9.1)$ \\
\hline \multicolumn{2}{|l|}{ Types of spondylarthropathies } \\
\hline Ankylosing spondylitis ${ }^{\mathrm{a}}$ & $94(72)$ \\
\hline Undifferentiated spondylarthropathy ${ }^{\mathrm{a}}$ & $15(12)$ \\
\hline Psoriatic arthritis $^{\mathrm{a}}$ & $11(8)$ \\
\hline SpA and inflammatory bowel disease ${ }^{a}$ & $5(4)$ \\
\hline Reactive arthritis ${ }^{\mathrm{a}}$ & $5(4)$ \\
\hline \multicolumn{2}{|l|}{ Disease-related variables } \\
\hline Time since diagnosis ${ }^{\mathrm{c}}$ (months) & $6.6(2.3-14.9)$ \\
\hline Disease duration $^{c}$ (years) & $6.3(3.2-11.3)$ \\
\hline HLA-B2 $7^{\mathrm{a}}$, positive & $96(74)$ \\
\hline $\operatorname{ESR}^{\mathrm{c}}(\mathrm{mm} / \mathrm{h})$ & $9.0(4.3-18.8)$ \\
\hline $\mathrm{CRP}^{\mathrm{c}}(\mathrm{mg} / \mathrm{l})$ & $5.0(2.0-12.0)$ \\
\hline $\operatorname{BASFI}^{\mathrm{c}}(0-10)$ & $2.4(0.9-4.5)$ \\
\hline $\operatorname{BASDAI}^{\mathrm{b}}(0-10)$ & $4.2(2.3)$ \\
\hline $\operatorname{BASMI}^{\mathrm{c}}(0-10)$ & $1.0(0.0-2.3)$ \\
\hline Uveitis $^{\mathrm{a}}$ & $31(24)$ \\
\hline Psoriasis $^{\mathrm{a}}$ & $11(9)$ \\
\hline Inflammatory bowel disease $^{\mathrm{a}}$ & $5(4)$ \\
\hline Peripheral arthritis ${ }^{\mathrm{a}}$ & $43(33)$ \\
\hline NSAIDs $^{\mathrm{a}}$ & $123(95)$ \\
\hline DMARDs $^{\mathrm{a}}$ & $6(5)$ \\
\hline Biologicals $^{\mathrm{a}}$ & $2(2)$ \\
\hline
\end{tabular}

Other BMD-related variables

$\operatorname{BMI}^{\mathrm{b}}\left(\mathrm{kg} / \mathrm{m}^{2}\right)$

Postmenopausal status ${ }^{\mathrm{a}}(N=44)$

$53(41)$
Table 1 (continued)

\begin{tabular}{ll}
\hline & $N=130$ \\
\hline BMD variables & \\
BMD femur $^{\mathrm{b}}$ & $0.940(0.170)$ \\
$T$ score femur $^{\mathrm{b}}$ & $-0.37(1.06)$ \\
$Z$ score femur $^{\mathrm{b}}$ & $-0.32(1.00)$ \\
BMD lumbar spine $^{\mathrm{b}}$ & $1.102(0.216)$ \\
$T$ score lumbar spine $^{\mathrm{b}}$ & $-0.42(1.51)$ \\
$Z$ score lumbar spine $^{\mathrm{b}}$ & $-0.46(1.51)$
\end{tabular}

ESR erythrocyte sedimentation rate, $C R P$ C-reactive protein, $B A S D A I$ Bath Ankylosing Spondylitis Disease Activity Index, BASFI Bath Ankylosing Spondylitis Functional Index, BASMI Bath Ankylosing Spondylitis Metrology Index, NSAIDs non-steroidal anti-inflammatory drugs, DMARDs disease-modifying anti-rheumatic drugs, $B M I$ body mass index

${ }^{\text {a }}$ Number $(\%)$

${ }^{\mathrm{b}}$ Mean (SD)

${ }^{\mathrm{c}}$ Median (IQR)

Only two women were postmenopausal, one of them with a low and the other with a normal BMD. None of the patients had a history of symptomatic vertebral fractures or of osteoporotic peripheral fractures. Furthermore, none of them had a drug history of corticosteroids or bisphosphonates, and most patients (95\%) were being treated with NSAIDs.

\section{BMD measurements}

All patients had a BMD measurement at a median period of 6.6 months (2.3-14.9 months) after diagnosis. Osteopenia was present in $38 \%$ of the patients and osteoporosis in $9 \%$, whereas half of the early SpA population had a normal BMD (Table 2). In this early SpA patient group, no significant differences in the distribution of normal BMD, osteopenia, and osteoporosis were found between hip and lumbar spine.

Relation between BMD and disease-related variables in early $\mathrm{SpA}$ patients

Differences between characteristics of SpA patients with low BMD (osteopenia and/or osteoporosis) and normal BMD are summarized in Table 3. Univariate analyses in this table demonstrate that $\mathrm{SpA}$ patients with low BMD were significantly more often male, had more often the diagnosis AS, showed higher CRP levels, and had higher BASFI and BASMI scores than patients with normal BMD.

No significant differences were found regarding age, time since diagnosis, disease duration, HLA-B27, ESR, BASDAI, extra-spinal manifestations, BMI, previous non-vertebral 
Table 2 Prevalence of normal BMD, osteopenia, and osteoporosis in early $\mathrm{SpA}$ patients

\begin{tabular}{lccl}
\hline & Femur & Lumbar spine & Femur and lumbar spine \\
\hline Normal BMD & $90(69.2 \%)$ & $80(61.5 \%)$ & $70(53.8 \%)$ \\
Osteopenia & $37(28.5 \%)$ & $40(30.8 \%)$ & $49(37.7 \%)$ \\
Osteoporosis & $3(2.3 \%)$ & $10(7.7 \%)$ & $11(8.5 \%)$ \\
\hline
\end{tabular}

Normal $\mathrm{BMD}=T$ score $\geq-1.0$, osteopenia $=-2.5<T$ score $<-1.0$, osteoporosis $=T$ score $\leq-2.5$

fractures, and postmenopausal status. The use of NSAIDs, DMARDs, and biologicals showed no differences between the two groups with low and normal BMD. Nearly all patients in each group (93\% vs. $96 \%$ ) were treated with NSAIDs. Only three patients in both groups used DMARDs, and only two patients in the low BMD group were treated with biologicals.

On univariate logistic regression analysis (Table 4), male gender, AS diagnosis, increased CRP, high BASFI, and high BASMI were significantly associated with low BMD (i.e., osteopenia and/or osteoporosis).

On multivariate logistic regression analysis (Table 4), male gender, high BASMI, and high BASFI remained associated with low BMD. These three variables had an explained variation of $30.5 \%$ in the multivariate model.

The relation between gender and BMD levels clearly shows (univariate and multivariate) that male patients with $\mathrm{SpA}$ are more prone to develop low BMD at an early stage of the disease than female patients. In 86 men, only $41 \%$ had normal BMD, $47 \%$ had osteopenia, and $12 \%$ already had osteoporosis. Among 44 (mostly premenopausal)

Table 3 Comparison of early SpA patients with low and normal BMD

\begin{tabular}{|c|c|c|c|}
\hline & Low BMD $(N=60)$ & Normal BMD $(N=70)$ & $p$ value \\
\hline \multicolumn{4}{|l|}{ Demographic variables } \\
\hline $\operatorname{Men}^{\mathrm{a}}$ & $50(83.3)$ & $36(51.4)$ & $<0.001$ \\
\hline $\operatorname{Age}^{\mathrm{b}}$ (years) & $38.1(8.9)$ & $38.0(9.3)$ & NS \\
\hline \multicolumn{4}{|l|}{ Disease-related variables } \\
\hline Time since diagnosis ${ }^{\mathrm{c}}$ (months) & $7.7(3.0-15.0)$ & $5.9(1.9-14.9)$ & NS \\
\hline Disease duration $^{\mathrm{c}}$ (years) & $6.7(3.8-13.8)$ & $6.1(2.1-10.3)$ & NS \\
\hline Ankylosing spondylitis ${ }^{\mathrm{a}}$ & $49(81.7)$ & $45(64.3)$ & 0.027 \\
\hline HLA-B27, positivity $^{\mathrm{a}}$ & $43(71.7)$ & $53(75.7)$ & NS \\
\hline $\operatorname{ESR}^{\mathrm{c}}(\mathrm{mm} / \mathrm{hr})$ & $9.0(5.0-21.0)$ & $9.0(4.0-17.5)$ & NS \\
\hline $\mathrm{CRP}^{\mathrm{c}}(\mathrm{mg} / \mathrm{l})$ & $9.0(2.0-15.0)$ & $3.5(1.8-7.0)$ & 0.008 \\
\hline BASDAI $^{\mathrm{b}}(0-10)$ & $4.4(2.4)$ & $4.1(2.2)$ & NS \\
\hline $\operatorname{BASFI}^{\mathrm{c}}(0-10)$ & $3.5(1.1-6.1)$ & $1.8(0.7-3.7)$ & 0.004 \\
\hline $\operatorname{BASMI}^{\mathrm{c}}(0-10)$ & $2.0(1.0-3.0)$ & $1.0(0.0-2.0)$ & $<0.001$ \\
\hline Uveitis $^{\mathrm{a}}$ & $11(18.3)$ & $20(28.6)$ & NS \\
\hline Psoriasis $^{\mathrm{a}}$ & $5(8.3)$ & $6(8.6)$ & NS \\
\hline Inflammatory bowel disease $^{\mathrm{a}}$ & $2(3.3)$ & $3(4.3)$ & NS \\
\hline Peripheral arthritis ${ }^{\mathrm{a}}$ & $14(23.3)$ & $29(41.4)$ & NS \\
\hline \multicolumn{4}{|l|}{ Other BMD-related variables } \\
\hline $\mathrm{BMI}^{\mathrm{b}}\left(\mathrm{kg} / \mathrm{m}^{2}\right)$ & $24.7(3.6)$ & $25.2(4.0)$ & NS \\
\hline Postmenopausal status ${ }^{\mathrm{a}}$ & $1(1.7)$ & $1(1.4)$ & NS \\
\hline Previous non-vertebral fractures ${ }^{a}$ & $22(36.7)$ & $31(44.3)$ & NS \\
\hline
\end{tabular}

$N S$ not significant $(p \geq 0.05), E S R$ erythrocyte sedimentation rate, CRP C-reactive protein, BASDAI Bath Ankylosing Spondylitis Disease Activity Index, BASFI Bath Ankylosing Spondylitis Functional Index, BASMI Bath Ankylosing Spondylitis Metrology Index, BMI body mass index

${ }^{\mathrm{a}}$ Number (\%)

${ }^{\mathrm{b}}$ Mean (SD)

${ }^{\mathrm{c}}$ Median (IQR) 
Table 4 Relation between disease-related variables and low BMD

\begin{tabular}{|c|c|c|c|c|}
\hline \multirow[b]{2}{*}{ Variables } & \multicolumn{2}{|l|}{ Univariate } & \multicolumn{2}{|l|}{ Multivariate } \\
\hline & Odds ratio $(\mathrm{CI})$ & $p$ value & Odds ratio $(\mathrm{CI})$ & $p$ value \\
\hline Men & $4.72(2.10-10.78)$ & $<0.001$ & $4.18(1.73-10.09)$ & 0.002 \\
\hline Ankylosing spondylitis & $2.48(1.09-5.60)$ & 0.030 & $1.54(0.61-3.86)$ & 0.359 \\
\hline CRP & $1.04(1.01-1.08)$ & 0.018 & $1.03(0.99-1.07)$ & 0.198 \\
\hline BASFI $(0-10)$ & $1.24(1.07-1.44)$ & 0.004 & $1.18(1.00-1.39)$ & 0.053 \\
\hline BASMI $(0-10)$ & $1.72(1.32-2.25)$ & $<0.001$ & $1.54(1.14-2.07)$ & 0.005 \\
\hline
\end{tabular}

CRP C-reactive protein, BASFI Bath Ankylosing Spondylitis Functional Index, BASMI Bath Ankylosing Spondylitis Metrology Index

women, $77 \%$ had normal BMD, $21 \%$ osteopenia, and $2 \%$ osteoporosis. To summarize, there was a significant difference between men and women with regard to the development of low BMD. Male patients turned out to have higher BASMI scores than female patients (data not shown).

\section{Discussion}

This study shows a high prevalence $(47 \%)$ of low BMD in both femur and lumbar spine in SpA patients with early disease. Low BMD proved to be significantly associated with male gender and the severity of the disease, as shown by high BASMI and BASFI levels. Our study is the first to report on BMD status in an early SpA population, which is in contrast with other studies reporting only on AS. Furthermore, even in most "early AS studies", AS patients usually have longer disease durations [19-21].

Osteoporosis is a well-known complication of longstanding AS. However, studies about the degree of osteoporosis in a $\mathrm{SpA}$ population and its relation with risk factors are limited, particularly in patients with an early disease. Traditional risk factors affecting the BMD state in the general population are female gender, increasing age, low body mass index, menopause, and the presence of chronic inflammatory diseases. No significant differences were found between SpA patients with low and normal BMD in terms of these risk factors in this study. In contrast with the general population, in this study, low BMD values were particularly found in relatively young men instead of women who usually have lower BMD values due to lower peak bone mass and bone loss during menopause, although the number of postmenopausal women in this study was very low. The relatively high prevalence of osteoporosis in male patients could be explained by a higher disease activity in men compared with women, although this could not be demonstrated (with the BASDAI) in our crosssectional study. Another possibility could be a difference in hormone levels, testosterone, and estrogen in AS patients (compared with the healthy population), although observa- tions in previous studies were not conclusive on this subject [22-25] and could not explain the early onset of osteoporosis in male patients. However, it is possible that premenopausal women are less prone to SpA-related bone loss than male patients due to the protective action of estrogen.

In $\mathrm{SpA}$ (especially AS), other potential risk factors for bone loss occur, such as inflammation and mechanical factors: rigidity of the spine resulting in limited mobility and reduced physical activity due to pain and stiffness. Data about these risk factors, high disease activity variables such as ESR, CRP, BASDAI, as well as indicators of low functional capacity such as high BASFI and BASMI scores, are not consistently reported in relation with low BMD levels in different studies [2, 19, 20]. In this study, disease activity parameters, such as increased CRP and high BASFI and BASMI scores, correlated significantly with low bone mass in femoral neck as well as in lumbar spine. Inflammation in $\mathrm{SpA}$ and decreased functional capacity turned out to be major contributors to this process.

The role of pro-inflammatory cytokines might be important for the onset of osteoporosis because increased TNF-alpha levels have been found in patients with AS compared with subjects with non-inflammatory back pain, and correlations have been found between disease activity and markers associated with an increased bone metabolism [26]. This supports the hypothesis that increased inflammatory activity in AS will lead to increased bone resorption and decreased bone density.

Mechanical factors, such as rigidity of the spine due to ankylosis, seem to be a less likely explanation for low BMD in our group of patients because they were relatively young and had a short disease duration. The fact that low BMD is encountered in a young population with an early disease is very interesting. In most other studies, "early" often refers to patients who have not yet developed ankylosis or other radiological progression signs, or these studies made use of disease durations as time since diagnosis and then referred to a disease duration of $<10$ years [19-21]. The issue of defining disease duration has been much debated in the AS 
literature, and with the knowledge of today, the onset of the first symptoms is considered to be most important [27]. The majority of the early SpA patients included in this study had a short time since diagnosis (median of 6.6 months) and disease duration (median of 6.3 years), counting from the very first symptoms of axial manifestations (i.e., inflammatory back pain or AS specific symptoms), which is shorter than the mean duration of $8-10$ years before diagnosis, as mentioned in the literature [28-30].

Low BMD in this early SpA group is equally prevalent in femur and spine, although osteoporosis is slightly more prevalent in the spine $(7.7 \%)$ compared with the femur $(2.3 \%)$. This observation is in contrast with long-standing AS in which reduced bone mass is particularly reflected by low BMD in the hips. The lumbar spine often shows misleading high BMD values due to bridging syndesmophytes and ankylosis, which might mask osteoporosis in AS patients with an advanced disease [1, 2, 10, 11]. Although it seems unlikely that many syndesmophytes and ankylosis of the vertebrae have developed already at such an early stage of the disease, we checked the radiographs of the lumbar spine. Only a few patients (nine patients) had a small syndesmophyte which did not influence the presented results of the analyses (data not shown).

Finally, a relatively small group (28\%) of our early SpA cohort had diagnoses other than AS, of which $31 \%$ turned out to have a low BMD. In the univariate analysis, the diagnosis AS seemed to be significantly related to low BMD, but after correction for other risk factors in the multivariate model, this association was not found. Therefore, patients with spondylarthropathies as a group are prone to have low BMD at an early stage of the disease.

In conclusion, this study demonstrates that half of the early SpA patients already show low BMD. Especially men at a relatively young age with high disease severity (indicated by impaired physical function with high BASMI and BASFI levels) are prone to have low BMD, and there is a strong tendency for an association with the diagnosis AS and high CRP. At early stages of the disease, no differences are found in low BMD between hips and spine.

These findings are clinically relevant since reduced bone mass will increase the risk of vertebral deformities and fractures. Therefore, we would like to emphasize the need for more alertness for osteoporosis and osteopenia in spondylarthropathy patients at an early stage of the disease.

\section{Disclosures None.}

Open Access This article is distributed under the terms of the Creative Commons Attribution Noncommercial License which permits any noncommercial use, distribution, and reproduction in any medium, provided the original author(s) and source are credited.

\section{References}

1. Donnelly S, Doyle DV, Denton A, Rolfe I, McCloskey EV, Spector TD (1994) Bone mineral density and vertebral compression fracture rates in ankylosing spondylitis. Ann Rheum Dis 53 (2):117-121

2. Karberg K, Zochling J, Sieper J, Felsenberg D, Braun J (2005) Bone loss is detected more frequently in patients with ankylosing spondylitis with syndesmophytes. J Rheumatol 32(7):1290-1298

3. Mitra D, Elvins DM, Speden DJ, Collins AJ (2000) The prevalence of vertebral fractures in mild ankylosing spondylitis and their relationship to bone mineral density. Rheumatology (Oxford) 39(1):85-89

4. Ralston SH, Urquhart GD, Brzeski M, Sturrock RD (1990) Prevalence of vertebral compression fractures due to osteoporosis in ankylosing spondylitis. BMJ 300(6724):563-565

5. Cooper C, Carbone L, Michet CJ, Atkinson EJ, O'Fallon WM, Melton LJ III (1994) Fracture risk in patients with ankylosing spondylitis: a population based study. J Rheumatol 21(10):1877-1882

6. Geusens P, Vosse D, van der Heijde D, Vanhoof J, van TA, Raus J et al (2001) High prevalence of thoracic vertebral deformities and discal wedging in ankylosing spondylitis patients with hyperkyphosis. J Rheumatol 28(8):1856-1861

7. Osgood CP, Abbasy M, Mathews T (1975) Multiple spine fractures in ankylosing spondylitis. J Trauma 15(2):163-166

8. Grisolia A, Bell RL, Peltier LF (1967) Fractures and dislocations of the spine complicating ankylosing spondylitis. A report of six cases. J Bone Joint Surg Am 49(2):339-344

9. Jacobs WB, Fehlings MG (2008) Ankylosing spondylitis and spinal cord injury: origin, incidence, management, and avoidance. Neurosurg Focus 24(1):E12

10. Lanyi E, Gomor B, Ratko I (1997) Determination of diminished bone mineral density in ankylosing spondylitis. Orv Hetil 138 (36):2227-2229

11. Mullaji AB, Upadhyay SS, Ho EK (1994) Bone mineral density in ankylosing spondylitis. DEXA comparison of control subjects with mild and advanced cases. J Bone Joint Surg Br 76(4):660-665

12. Dougados M, van der Linden S, Juhlin R, Huitfeldt B, Amor B, Calin A et al (1991) The European Spondylarthropathy Study Group preliminary criteria for the classification of spondylarthropathy. Arthritis Rheum 34(10):1218-1227

13. Calin A, Porta J, Fries JF, Schurman DJ (1977) Clinical history as a screening test for ankylosing spondylitis. JAMA 237(24):2613-2614

14. van der Linden S, Valkenburg HA, Cats A (1984) Evaluation of diagnostic criteria for ankylosing spondylitis. A proposal for modification of the New York criteria. Arthritis Rheum 27(4):361-368

15. Garrett S, Jenkinson T, Kennedy LG, Whitelock H, Gaisford P, Calin A (1994) A new approach to defining disease status in ankylosing spondylitis: the Bath Ankylosing Spondylitis Disease Activity Index. J Rheumatol 21(12):2286-2291

16. Calin A, Garrett S, Whitelock H, Kennedy LG, O'Hea J, Mallorie $\mathrm{P}$ et al (1994) A new approach to defining functional ability in ankylosing spondylitis: the development of the Bath Ankylosing Spondylitis Functional Index. J Rheumatol 21(12):2281-2285

17. Jenkinson TR, Mallorie PA, Whitelock HC, Kennedy LG, Garrett SL, Calin A (1994) Defining spinal mobility in ankylosing spondylitis (AS). The Bath AS Metrology Index. J Rheumatol 21 (9):1694-1698

18. [No authors listed] (1994) Assessment of fracture risk and its application to screening for postmenopausal osteoporosis. Report of a WHO Study Group. World Health Organ Tech Rep Ser 843:1-129

19. Gratacos J, Collado A, Pons F, Osaba M, Sanmarti R, Roque M et al (1999) Significant loss of bone mass in patients with early, active ankylosing spondylitis: a followup study. Arthritis Rheum 42(11):2319-2324 
20. Toussirot E, Michel F, Wendling D (2001) Bone density, ultrasound measurements and body composition in early ankylosing spondylitis. Rheumatology (Oxford) 40(8):882-888

21. Will R, Palmer R, Bhalla AK, Ring F, Calin A (1989) Osteoporosis in early ankylosing spondylitis: a primary pathological event? Lancet 2(8678-8679):1483-1485

22. Franck H, Meurer T, Hofbauer LC (2004) Evaluation of bone mineral density, hormones, biochemical markers of bone metabolism, and osteoprotegerin serum levels in patients with ankylosing spondylitis. J Rheumatol 31(11):2236-2241

23. Giltay EJ, Popp-Snijders C, van SD, kker-Saeys BJ, Gooren LJ, Dijkmans BA (1998) Serum testosterone levels are not elevated in patients with ankylosing spondylitis. J Rheumatol 25(12):2389-2394

24. Giltay EJ, van SD, Gooren LJ, Popp-Snijders C, Dijkmans BA (1999) Androgens and ankylosing spondylitis: a role in the pathogenesis? Ann NY Acad Sci 876:340-364

25. Gooren LJ, Giltay EJ, van SD, Dijkmans BA (2000) Gonadal and adrenal sex steroids in ankylosing spondylitis. Rheum Dis Clin North Am 26(4):969-987
26. Lange U, Teichmann J, Stracke H (2000) Correlation between plasma TNF-alpha, IGF-1, biochemical markers of bone metabolism, markers of inflammation/disease activity, and clinical manifestations in ankylosing spondylitis. Eur J Med Res 5 (12):507-511

27. Davis JC, Dougados M, Braun J, Sieper J, van der Heijde D, van der Linden S (2006) Definition of disease duration in ankylosing spondylitis: reassessing the concept. Ann Rheum Dis 65 (11): $1518-1520$

28. Dincer U, Cakar E, Kiralp MZ, Dursun H (2008) Diagnosis delay in patients with ankylosing spondylitis: possible reasons and proposals for new diagnostic criteria. Clin Rheumatol 27(4):457-462

29. Feldtkeller E, Khan MA, van der Heijde D, van der Linden S, Braun J (2003) Age at disease onset and diagnosis delay in HLAB27 negative vs. positive patients with ankylosing spondylitis. Rheumatol Int 23(2):61-66

30. Feldtkeller E, Erlendsson J (2008) Definition of disease duration in ankylosing spondylitis. Rheumatol Int 28(7):693-696 